\title{
CLASSES FUNCIONAIS E DE EQUIVALENCIA DERIVADAS DE LINHA DE BASE DE DISCRIMINAÇÕES SIMPLES E CONDICIONAIS EM CRIANÇAS
}

\author{
FUNCTIONAL AND EQUIVALENCE CLASSES DERIVED FROM A BASELINE OF SIMPLE \\ AND CONDITIONAL DISCRIMINATIONS IN CHILDREN
}

\author{
Daniela de Souza Canovas, Lidia Maria Marson Postalli e Deisy das Graças de Souza \\ UNIVERSIDADE FEDERAL DE SÃO CARLOS ${ }^{1}$
}

\begin{abstract}
RESUMO
Classes funcionais podem ser estabelecidas a partir do ensino de discriminações simples e reversões repetidas. Apesar de eficiente, esse procedimento pode favorecer a ocorrência de erros, com possíveis interferências na formação de classes. O objetivo deste estudo foi investigar os efeitos de um procedimento de ensino sem reversões sobre a aprendizagem de discriminações simples e condicionais, sobre a transferência de funções entre estímulos e sobre a formação de classes funcionais e de equivalência, em crianças pré-escolares. As crianças aprenderam três discriminações simples, e os estímulos S+ e S- de um desses pares eram incluídos como modelos em uma tarefa de discriminação condicional, com um novo par de estímulos de comparação. Os seis participantes aprenderam as discriminações simples e condicionais, com um número relativamente pequeno de erros. As sondas eram misturadas com tentativas de linha de base de discriminação simples e condicional. Nas sondas de discriminação simples com o par de estímulos que só haviam tido função de estímulos de comparação, todas as crianças selecionaram o estímulo que havia sido correlacionado com o modelo que teve função de S+ na linha de base de discriminações simples (transferência de funções). Nos testes de discriminações condicionais, três participantes apresentaram emergência (imediata ou atrasada) de novas relações, o que pode ser interpretado como formação de classes funcionais. Dois dos participantes foram, então, expostos ao ensino de novas discriminações condicionais e responderam nas sondas de discriminação simples e condicional de acordo com as funções de estímulo estabelecidas no treino (formação de classes funcionais e de equivalência). A variabilidade entre participantes foi similar à observada em procedimentos com reversão, que geraram mais erros do que este estudo, o que sugere que a ocorrência de erros não é uma variável crítica na explicação da variabilidade.
\end{abstract}

Palavras-chave: discriminação simples, discriminação condicional, classes funcionais, classes de equivalência, crianças pré-escolares.

\begin{abstract}
Functional classes can be established thorough simple discrimination and repeated reversals training. However, successive reversals necessarily involve experience with the occurrence of errors, which may interfere with class formation. The purpose of this study was to investigate the effects of a teaching procedure with no reversals on the acquisition of simple and conditional discriminations, on the transfer of stimulus functions, and on the formation of functional and equivalence classes, in preschool children. The children learned three simple discriminations and the $\mathrm{S}^{+}$and $\mathrm{S}^{-}$of one of the discriminations were presented as samples in a matching-to-sample task with a novel pair of comparison stimuli. Six participants learned the simple and conditional discriminations with a few errors. Probe trials were inserted among trials of a baseline of simple and conditional discriminations. In probes of simple discrimination with the stimuli that served as comparisons in the conditional discrimination, all children selected the novel stimulus correlated with the sample that had a previous $\mathrm{S}^{+}$function in a simple discrimination. In conditional discriminations probes, participants showed emergence of new relations (immediate or delayed), what can be interpreted as the formation of functional classes. Then, two participants learned new conditional discriminations and responded in simple and conditional discrimination probes according to the stimulus functions established in training (formation of functional and equivalence classes). The variability in individual performances was similar to that observed under reversal procedures, which generated more errors than the present study, thus suggesting that errors are not the critical variable responsible for the variability.
\end{abstract}

Keywords: simple discrimination, conditional discrimination, functional classes, equivalence classes, preschool children.

A formação de classes de estímulos dissimilares arbitrariamente relacionados constitui um processo básico na aprendizagem de comportamentos simbólicos complexos, que incluem, por exemplo, formação de conceitos ou categorias, abstração, resolução de problemas, entre outros (de Rose, 1993; Sidman, 1994). Classes de estímulos podem ser formadas a partir de discriminações condicionais (contingências de quatro termos)

\footnotetext{
${ }^{1}$ Instituto Nacional de Ciência e Tecnologia sobre Comportamento, Cognição e Ensino.
} 
designadas, nesse caso, como classes de equivalência, ou a partir de discriminações simples (contingência de três termos), definidas como classes funcionais (de Rose, 1993).

As classes funcionais ocasionam respostas de uma mesma classe na presença dos estímulos que as compõem (de Rose, 1993; Goldiamond, 1966). A aprendizagem dessas relações pode ocorrer a partir de treinos em que uma resposta comum é inicialmente estabelecida na presença de cada um dos estímulos. As contingências em operação devem ser similares em relação a estímulos membros de uma mesma classe e diferenciadas em relação a estímulos de outras classes (Goldiamond, 1962; Keller \& Schoenfeld, 2004). A demonstração da formação de uma classe funcional, no entanto, exige que variáveis aplicadas diretamente a um estímulo exerçam efeito também em relação aos demais membros da classe. Assim, diferentes estímulos discriminativos pertencentes a uma mesma classe funcional tornam-se substituíveis no controle de uma resposta comum (Goldiamond, 1962, 1966).

O procedimento comumente utilizado para gerar classes funcionais tem sido o treino de discriminações simples e reversões repetidas. Esse procedimento foi utilizado originalmente por Vaughan (1988), em um estudo realizado com pombos. Os estímulos utilizados eram 40 slides com figuras de árvores, divididos em dois subconjuntos: um designado com função de $\mathrm{S}^{+}(20$ slides $)$ e o outro com função de $\mathrm{S}^{-}$(outros 20 slides). As figuras eram apresentadas de acordo com um procedimento de discriminação sucessiva (go/no-go) em sessões de 80 tentativas (duas tentativas de cada estímulo). Depois que os pombos apresentaram responder estável e acurado na presença dos $\mathrm{S}^{+}$e baixa frequên- cia de respostas na presença dos $\mathrm{S}^{-}$, eram realizadas repetidas e sistemáticas reversões das contingências. A cada reversão, os estímulos definidos como $\mathrm{S}^{+}$na condição anterior passavam a funcionar como $\mathrm{S}^{-}$, e vice-versa. Depois de repetidas reversões nas contingências, o desempenho dos pombos tornou-se cada vez mais preciso antes mesmo da exposição a todos os estímulos do conjunto: a uma nova reversão, a exposição a poucos exemplares era suficiente para sustentar o responder subsequente sob controle das classes (classe dos $\mathrm{S}^{+}$e dos $\mathrm{S}^{-}$).

O procedimento de treino de discriminações simples e reversões repetidas foi empregado em um estudo realizado com seis crianças pequenas com desenvolvimento típico e seis crianças diagnosticadas com autismo (Lionello-DeNolf, McIlvane, Canovas, de Souza, \& Barros, 2008). As crianças com desenvolvimento típico eram expostas ao ensino de discriminações simples simultâneas entre três pares de estímulos, com repetidas reversões das contingências. Sondas de formação de classes eram realizadas ao longo das diversas reversões. As reversões eram realizadas como previsto, exceto que um par de estímulos era omitido das primeiras sessões e, na sequência, era apresentado como medida de sonda (o desempenho em relação a esse par era avaliado desde a primeira tentativa de sonda, o que indicaria ou não se o responder estaria sob controle das classes; Dube, Callahan, \& McIlvane, 1993). A cada reversão era variado o par omitido para garantir a medida de sonda em relação a todos os pares. Os dados indicaram efeitos de learning set (Harlow, 1949) para todas as crianças e evidências de formação de classes funcionais para três crianças. Uma reanálise dos resultados do Experimento 1 do estudo 
de Lionello-DeNolf et al. e de uma pesquisa subsequente, em que outras seis crianças foram expostas ao procedimento de reversões de discriminações simples simultâneas (desta vez com três e quatro pares de estímulos), mostrou que aproximadamente seis das 12 crianças formaram classes funcionais (Canovas, 2010). Os resultados dessa replicação, com o emprego de reversões de discriminações sucessivas (em vez de simultâneas), com cinco crianças, indicaram que duas das cinco crianças formaram classes funcionais. Duas das crianças expostas ao procedimento de discriminações simultâneas, e uma das crianças exposta ao procedimento de discriminações sucessivas apresentaram número crescente de erros em algumas das fases de reversões, ou seja, indícios de efeitos deletérios de erros (Stoddard, de Rose, \& McIlvane, 1986) e indícios de estabelecimento de topografias de controle de estímulos concorrentes com aquelas planejadas no experimento (McIlvane \& Dube, 2003). Dessa forma, a ocorrência de erros, aspecto inerente ao procedimento de reversões, pode interferir na formação de classes, o que justificaria a investigação de procedimentos sem o emprego de reversões de discriminações simples para estabelecer classes funcionais.

Outra justificativa para a investigação de procedimentos diferentes do treino de discriminações simples e reversões repetidas é o argumento levantado por alguns autores (e.g., Saunders, Williams, \& Spradlin, 1996; Sidman, 1994) de que esse procedimento não implicaria necessariamente responder emergente, considerando que, nesse caso, a emergência de repertório é avaliada ao longo da exposição às condições de ensino e sob reforçamento (Sidman, 1994). Portanto, o produto comportamental observado pode- ria ser resultado direto da história de treino e não indicativo de emergência de repertório novo. Para atestar a formação de classes funcionais e não meramente a ocorrência de responder sob controle das séries de combinações de estímulos apresentadas, seria necessária uma medida de teste independente do treino (Sidman, 1994; Saunders, Williams, \& Spradlin, 1996). A formação de classes funcionais poderia ser demonstrada quando variáveis aplicadas a um dos membros da classe afetassem também os demais membros (Goldiamond, 1962), por exemplo, por meio de testes de transferência de função (pois, se os estímulos são membros de uma mesma classe funcional, observa-se transferência de função entre eles).Assim, os resultados de teste implicariam desempenho totalmente novo, emitido em condições novas e diferentes daquelas empregadas no treino (Wirth \& Chase, 2002).

A formação de classes funcionais seria demonstrada, por exemplo, a partir do estabelecimento de uma resposta comum na presença de parte dos membros de uma classe e verificação de ocorrência dessa resposta diante dos demais estímulos integrantes da classe (teste de transferência de função), como realizado por Smeets, Barnes e Roche (1997). É importante ressaltar que Smeets et al., entretanto, estabeleceram uma diferenciação entre os termos classes de estímulos funcionais ou classes funcionais - que se referem, na perspectiva desses autores, a uma classe de estímulos discriminativos que controlam determinada classe de respostas - e classes de equivalência funcional, que se referem a relações emergentes, verificadas por meio de transferência de função entre estímulos. No presente trabalho, é utilizada a designação adotada por Sidman (1994) de classes fun- 
cionais ou "classes de contingência", para se referir ao que esses outros autores definem como equivalência funcional.

O objetivo do estudo de Smeets et al. (1997), realizado com 20 crianças com idades entre quatro e cinco anos, era verificar se uma classe de estímulos funcional, ou seja, uma classe de estímulos discriminativos que ocasionam uma mesma resposta, poderia resultar em formação de classes de equivalência funcional (considerando a diferenciação dos autores entre classes funcionais e equivalência funcional) e classes de equivalência. No ensino das discriminações eram utilizados estímulos visuais impressos em cartões dispostos sobre uma mesa, diante da qual a criança permanecia sentada de frente para o experimentador. Inicialmente, era realizado um pré-treino de discriminações condicionais, em que eram ensinadas as relações condicionais XY, entre os estímulos X1Y1 e X2Y2. A seguir, em relação a novos estímulos (A1, A2, B1 e B2), eram estabelecidas respostas comuns para cada classe funcional potencial (a mesma resposta para os estímulos de uma mesma classe, mas diferentes respostas para os estímulos de diferentes classes). Nesse caso, a tarefa da criança era colocar os cartões em posições específicas em um quadrante disposto sobre a superficie da mesa. A resposta 1 (R1) era colocar cada cartão-estímulo no retângulo acima à direita e a resposta 2 (R2) era colocar cada cartão na posição abaixo à esquerda do quadrante. A combinação de respostas instaladas diante de cada estímulo era a seguinte:A1-R1, A2-R2, B1-R1 e B2-R2. Depois de aprendidas essas discriminações com respostas diferenciais, eram estabelecidas novas respostas diante de parte dos estímulos: A1-R3 e A2-R4 (R3 consistia em colocar um cartão-estímulo acima à esquerda e R4, abaixo à direita) e novos testes avaliavam as respostas em relação aos demais estímulos (B1 e B2 - teste de transferência de função). Por fim, eram realizados testes de emparelhamento entre membros das classes funcionais (testes $\mathrm{AB}$ e $\mathrm{BA}$ ) para verificar a formação de classes de equivalência. Os resultados indicaram que a maioria das crianças aprendeu as tarefas, e grande parte delas demonstrou transferência de função discriminativa dos estímulos do conjunto A para o conjunto B (teste de classes funcionais), isto é, passaram a apresentar, sem treino direto, a resposta 3 (R3) na presença de B1 e a R4 na presença de B2. Considerando o teste de equivalência, 11 dos 15 participantes que demonstraram transferência de função também apresentaram responder emergente $(100 \%$ de acertos nas tentativas de teste das relações AB e BA), o que pode ser interpretado como formação de classes de equivalência. Os dados indicaram forte correlação entre os tipos de formação de classes, e os autores sugeriram que a equivalência funcional pode implicar equivalência de estímulos (Smeets et al., 1997).

Outros estudos empregaram o ensino de discriminações simples e condicionais e testes de transferência de função. Por exemplo, de Rose, McIlvane, Dube e Stoddard (1988) investigaram a relação entre formação de classes funcionais e desempenho emergente em discriminações condicionais. Um objetivo do estudo foi verificar o efeito da direção do treino, ou seja, quais seriam os resultados em tarefas em que os estímulos exercessem função de modelo ou de comparação. Os participantes, indivíduos adultos com retardo, eram inicialmente expostos ao ensino de uma discriminação simples simultânea A1+/A2-. 
Aprendida essa discriminação, era realizado o ensino das relações condicionais $\mathrm{AB}$, em que as respostas de seleção consideradas corretas e reforçadas eram escolher o estímulo B1 diante do modelo A1 e o estímulo B2 diante de A2. Na fase seguinte, em um mesmo bloco eram apresentadas tentativas de discriminação simples (A1+/A2-) e condicional $(\mathrm{AB})$, distribuídas em uma sequência randômica. Depois do estabelecimento dessa linha de base, era realizado um teste em que os estímulos B1 e B2 eram apresentados em tentativas de discriminação simples, visando a verificar se teriam adquirido função de $\mathrm{S}^{+}$ e de $\mathrm{S}^{-}$, respectivamente. $\mathrm{Na}$ segunda etapa desse estudo, eram ensinadas novas relações condicionais: BC e DB. A seguir, os participantes eram expostos a sessões em que eram apresentadas tentativas dos quatro tipos de relações ensinadas: discriminação simples (A1/A2) e discriminações condicionais (AB, $\mathrm{BC}$ e DB). Os demais testes realizados eram: 1. avaliação da função discriminativa em tentativas de discriminação simples para os pares C e D (avaliação de formação de classes funcionais); e 2. avaliação de emergência das relações CD (por meio de emparelhamento).

De forma geral, os participantes aprenderam as discriminações simples e condicionais ao longo das diferentes linhas de base. Os resultados do primeiro teste indicaram que os estímulos B1 e B2 adquiriram as mesmas funções discriminativas dos estímulos A1 e A2 aos quais haviam sido relacionados na fase anterior. Os resultados do segundo teste indicaram que: 1. os estímulos C1 e C2 adquiriram as funções discriminativas positiva e negativa, respectivamente (o que não ocorreu com os estímulos D1 e D2); 2. ocorreu emergência das relações CD. Os resultados do segundo teste sugeriram que a direção do treino resultou em diferentes histórias de aprendizagem, que afetaram o responder nas sondas, ou seja, quando B1 e B2 funcionaram como modelos e C1 e C2 como estímulos de comparação, ocorreu transferência; porém, quando estímulos D1 e D2 eram modelos e B1 e B2 eram estímulos de comparação, não foi observada transferência. Os autores concluíram que a transferência de função seria mais provável a partir dos estímulos modelo para os estímulos de comparação, considerando-se que os estímulos C1 e C2 que funcionaram como estímulos de comparação (treino BC) apresentaram as mesmas funções discriminativas dos estímulos a que foram relacionados, ao contrário dos estímulos D1 e D2, que funcionaram como modelo ao longo do treino (DB) (de Rose et al., 1988).

Dados positivos em testes de transferência de função também foram encontrados em estudos que empregaram tarefas de discriminação simples e condicional para investigar a emergência de discriminações em crianças pré-escolares de cinco anos de idade. Boelens e Smeets (1990) utilizaram um procedimento similar ao empregado na primeira etapa do estudo realizado por de Rose et al. (1988), em que eram ensinadas discriminações simples (A1+/A2-) e condicionais (AB). Na sequência, era testada a emergência da discriminação B1+/B2-. Os resultados indicaram emergência da discriminação, sugerindo que a transferência de função era provável quando os estímulos de treino (A1 e A2) precediam os estímulos de testes (B1 e B2), por exemplo, quando os estímulos do conjunto A funcionavam como modelo na tarefa de emparelhamento. 
Esse conjunto de dados descritos na literatura especializada sugere, portanto, a viabilidade de procedimentos de ensino de discriminações simples e condicionais alternadas com testes de transferência de função para se estabelecer e testar a emergência de classes funcionais e também investigar a relação entre os tipos de formação de classes (classes funcionais e classes de equivalência). Considerando a importância de se ampliar a base de dados sobre a emergência de desempenhos novos em crianças (visando a aumentar a generalidade de dados; Sidman, 1960) e refinar os conceitos de classes funcionais e de equivalência (Harzem \& Miles, 1978) a partir de dados sobre as condições sob as quais ocorrem, o presente estudo teve por objetivo avaliar os efeitos de um procedimento de ensino sem reversões sobre a aquisição de discriminações simples e condicionais, sobre a transferência de funções entre estímulos e sobre a formação de classes (funcionais e de equivalência). Para essa finalidade, o delineamento do procedimento obedeceu aos seguintes critérios: 1. não empregar reversões de discriminações simples; 2. garantir medidas de sondas independentes do treino (tentativas de teste em extinção); e 3. permitir avaliar se a formação de classes funcionais implicaria classes de equivalência (por meio de testes de relações condicionais emergentes entre os membros das classes funcionais previamente estabelecidas).

\section{MÉTOdo}

\section{Participantes}

Os participantes foram seis crianças pré-escolares (três meninos e três meninas) com idade entre três anos e 11 meses e quatro anos e um mês, que frequentavam uma creche assistencial de uma cidade do interior do Estado de São Paulo. As crianças participaram da pesquisa mediante autorização da instituição e consentimento dos pais, solicitados por escrito, após os devidos esclarecimentos sobre os objetivos do estudo. A pesquisa foi aprovada pelo Comitê de Ética da Universidade Federal de São Carlos (Protocolo CAAE 0156.0.000.135-07). A Tabela 1 resume os dados gerais de cada participante e apresenta os resultados da aplicação de instrumentos para avaliar seu repertório de entrada (PPVT-R, Dunn \& Dunn, 1981; e Teste de Triagem Denver II, Pedromônico, Bargatto \& Strobilus, 1999). Três crianças apresentavam indicação de atraso de linguagem.

Situação experimental, equipamentos e materiais

As sessões experimentais eram realizadas em uma sala da própria creche, mobiliada com mesas e cadeiras infantis e um armário com brinquedos. O computador utilizado para as sessões experimentais, um Macintosh, modelo iMac, foi instalado sobre uma mesa infantil com aproximadamente $50 \mathrm{~cm}$ de altura e um tampo de $80 \times 80 \mathrm{~cm}$. Para apresentação das tentativas e registro das respostas, foi utilizado o software MTS versão 11.6 (Dube, 1991; Dube \& Hiris, 1996).

A tarefa da criança consistia em posicionar o cursor (seta) sobre figuras apresentadas na tela e apertar o botão esquerdo do mouse (resposta de "clicar"). As sessões duravam aproximadamente cinco minutos e eram seguidas por um jogo ou brincadeira de escolha da criança, tais como quebra-cabeças, jogos de memória, bonecas, carimbos, material para pintura e desenho, adesivos, jogos de peças de encaixe. Ao longo das diferentes 
Tabela 1

Participantes, sexo, idade cronológica dos participantes no início do procedimento, idade no PPVT e desempenho no Denver II

\begin{tabular}{ccccc}
\hline Participantes $^{\star}$ & $\begin{array}{c}\text { Sexo } \\
(\text { F } / \mathrm{M})\end{array}$ & $\begin{array}{c}\text { Idade } \\
(\text { anos }- \text { meses })\end{array}$ & $\begin{array}{c}\text { Idade PPVT } \\
(\text { anos }- \text { meses })\end{array}$ & Desempenho Denver II \\
\hline Fábio & M & $3-11$ & $4-0$ & Normal \\
Bebel & F & $4-0$ & $3-7$ & Normal \\
Tuco & M & $4-0$ & $3-3$ & Atraso linguagem \\
Mili & F & $4-1$ & $3-1$ & Atraso linguagem \\
Nanda & F & $4-1$ & $4-2$ & Atraso motor fino \\
Juca & M & $4-1$ & $3-7$ & Atraso linguagem \\
\hline
\end{tabular}

* Os nomes são fictícios.

fases de ensino, o conjunto de brinquedos disponibilizados era variado.

\section{Estímulos}

Os estímulos eram pares de figuras abstratas coloridas, ilustradas na Figura 1.

\section{Procedimento}

Foram ensinadas discriminações simples simultâneas entre diferentes pares de estímulos e discriminações condicionais com dois estímulos de comparação. Cada sessão de ensino era composta por 30 tentativas. Nas fases de ensino, o critério de aprendizagem era de $96,6 \%$ de acertos (até um erro por sessão). Nas sessões de linha de base em esquema de reforçamento intermitente, que antecediam os testes, o critério era de $100 \%$ de acertos em duas sessões consecutivas, e nos testes o critério era a realização de três sessões consecutivas.

A sequência geral das tarefas experimentais realizadas é apresentada na Tabela 2. Em uma primeira etapa do procedimento, foram realizadas as oito primeiras fases listadas na tabela. O primeiro passo foi um pré-treino,

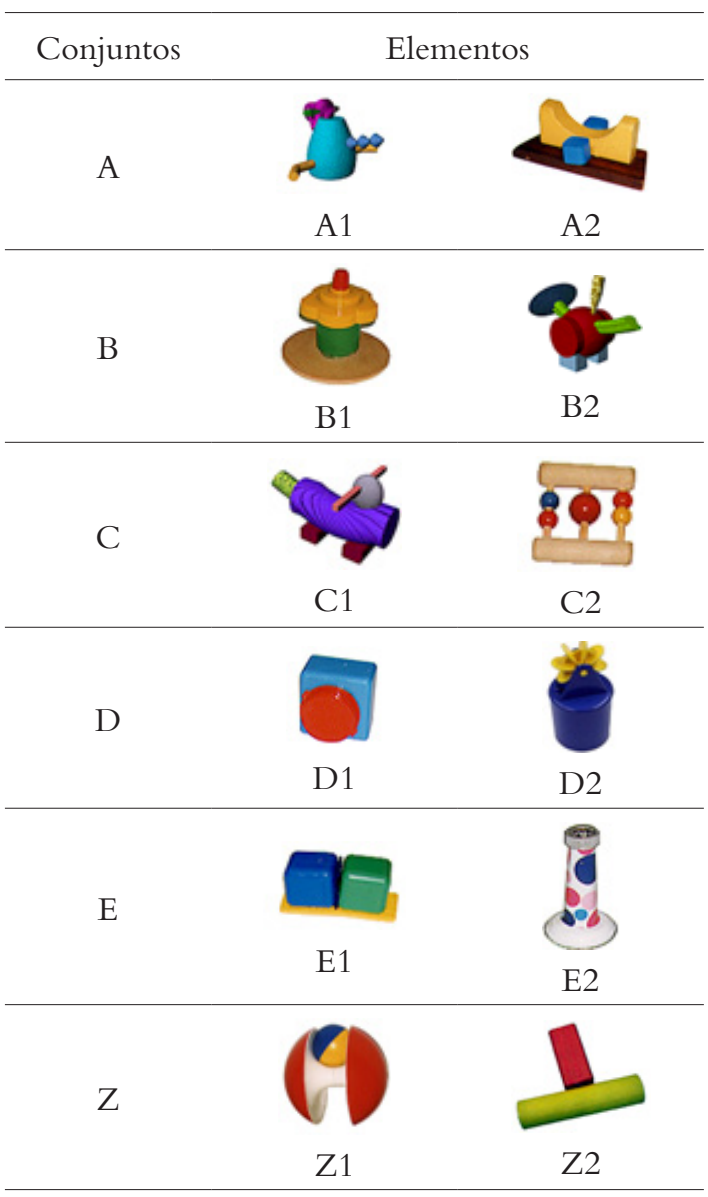

Figura 1. Estímulos empregados nas fases de ensino e teste do procedimento. 
realizado com o objetivo de familiarizar a criança com o computador e com as tarefas de discriminação simples e condicional. Em seguida, foram ensinadas três discriminações simples (A1/A2, B1/B2 e C1/C2) e discriminações condicionais entre os estímulos do conjunto A e os do conjunto Z (AZ), cada um com dois estímulos. A seguir, as tentativas de discriminação simples e condicional eram misturadas em uma mesma sessão. Sobre essa linha de base mista foram conduzidos testes de transferência de função: testes de discriminação simples (Z1/Z2), para verificar se esses estímulos adquiriram a função dos estímulos do conjunto A, a que foram relacionados na fase anterior, e testes de discriminações condicionais (BZ e CZ), para avaliar se os estímulos dos conjuntos $\mathrm{B}$ e $\mathrm{C}$ adquiriram a função de modelo em discriminações condicionais em que os estímulos Z1 e Z2 eram estímulos de comparação. Duas das crianças, entretanto, foram expostas ao ensino de duas discriminações simples (A1/A2 e B1/B2) e das discriminações condicionais AZ (e, nesse caso, ao teste das relações BZ apenas). O objetivo dessa manipulação era verificar se o número de discriminações ensinadas poderia influenciar os resultados dos testes de transferência de função. Nesse caso, as sessões eram constituídas por 20 tentativas, organizadas de forma análoga às sessões de 30 tentativas, sendo mantidos iguais o número de tentativas com cada discriminação e os critérios de aprendizagem.

$\mathrm{Na}$ segunda etapa do procedimento (ver Tabela 2, fases 9 a 13), foram ensinadas discriminações condicionais entre os estímulos do conjunto $\mathrm{Z}$ e novos estímulos (DZ e ZE). As novas relações foram ensinadas separadamente e depois incorporadas à linha de base mis- ta estabelecida previamente. A seguir, foram conduzidos testes de transferência de função para verificar a formação de classes funcionais em que os estímulos dos conjuntos novos foram, pela primeira vez, apresentados em tentativas de discriminações simples (D1/D2 e $\mathrm{E} 1 / \mathrm{E} 2)$; e testes de relações emergentes entre membros das classes funcionais para avaliar se a formação dessas classes implicaria classes de equivalência (teste das relações condicionais AD, DA e AE). A Figura 2 apresenta um diagrama das relações ensinadas e testadas. As setas contínuas representam discriminações condicionais ensinadas, e as setas tracejadas, as relações testadas. As letras representativas dos conjuntos de estímulos separadas por uma barra indicam discriminações simples ensinadas (quanto estiverem presentes os sinais + e - ) e relações testadas (sem a presença dos sinais).

\section{Pré-treino}

O objetivo geral do pré-treino foi familiarizar a criança com as contingências da sessão e modelar a resposta que seria colocada sob controle de estímulos nas etapas experimentais. Foram realizados dois passos de pré-treino: 1. tarefas de discriminação simples; 2. tarefas de discriminação condicional. Em ambos os passos os estímulos eram diferentes daqueles utilizados no procedimento experimental. Antes da exposição às sessões de pré-treino, a experimentadora fornecia instruções e/ou apresentava modelos de como manusear o mouse, bem como apresentava uma sequência de cinco tentativas, nas quais era apresentada uma figura em diferentes posições na tela, sobre a qual a criança deveria posicionar o cursor e apertar o botão esquerdo do mouse. Durante essa 
Tabela 2

Sequência das fases experimentais do procedimento (as siglas DS e DC referem-se às expressões discriminação simples e discriminação condicional, respectivamente)

\begin{tabular}{|c|c|c|}
\hline Sequência & Fase & Tarefas \\
\hline & & Etapa 1 \\
\hline 1 & Ensino & $\begin{array}{l}\text { Pré-treino: Ensino de discriminações simples K1/K2,V1/V2 e W1/W2 e } \\
\text { discriminações condicionais XY }\end{array}$ \\
\hline 2 & Ensino & $\begin{array}{l}\text { Linha de base DS: Ensino de discriminações simples separadas A1/A2, } \\
\qquad \text { B1/B2 e C1/C2 }\end{array}$ \\
\hline 3 & Ensino & $\begin{array}{l}\text { Linha de base DS: Ensino de discriminações simples alternadas A1/A2, } \\
\qquad \text { B1/B2 e C1/C2 }\end{array}$ \\
\hline 4 & Ensino & Linha de base DC: Ensino de discriminações condicionais AZ \\
\hline 5 & Ensino & $\begin{array}{l}\text { Linha de base mista A1/A2, B1/B2, C1/C2 e AZ com reforço contínuo, } \\
\text { seguida por reforço intermitente }\end{array}$ \\
\hline 6 & Teste & Teste de discriminação simples Z1/Z2 \\
\hline 7 & Ensino & $\begin{array}{l}\text { Linha de base mista A1/A2, B1/B2, C1/C2 e AZ com reforço contínuo, } \\
\text { seguida por reforço intermitente }\end{array}$ \\
\hline \multirow[t]{2}{*}{8} & Teste & Teste de discriminação condicional BZ e CZ \\
\hline & & Etapa 2 \\
\hline 9 & Ensino & Linha de base DC: Ensino de discriminações condicionais DZ e ZE \\
\hline 10 & Ensino & $\begin{array}{c}\text { Linha de base mista A1/A2, B1/B2, C1/C2, Z1/Z2, AZ, BZ, CZ, DZ e ZE } \\
\text { com reforço contínuo, seguida por reforço intermitente }\end{array}$ \\
\hline 11 & Teste & Teste de discriminação simples D1/D2 e E1/E2 \\
\hline 12 & Ensino & $\begin{array}{c}\text { Linha de base mista A1/A2, B1/B2, C1/C2, Z1/Z2, AZ, BZ, CZ, DZ e ZE } \\
\text { com reforço contínuo, seguida por reforço intermitente }\end{array}$ \\
\hline 13 & Teste & Teste de discriminação condicional AD, DA e AE \\
\hline
\end{tabular}

sessão, não havia consequências programadas para a resposta de "clicar", e a experimentadora apresentava dicas verbais e/ou fisicas e consequências para modelar o repertório da criança.

A primeira sessão de ensino de discriminação simples (Passo 1) era composta por 15 tentativas com os estímulos K1 e K2; nas primeiras cinco tentativas era apresentado apenas o estímulo $\mathrm{S}^{+}$(K1).A instrução inicial gravada no computador e apresentada simultaneamente à primeira tentativa era: "Aponte a flechinha na figura e, depois, aperte o botão." Respostas corretas eram consequenciadas com a apresentação de estrelas coloridas acompanhadas de uma série de sons ascendentes. 


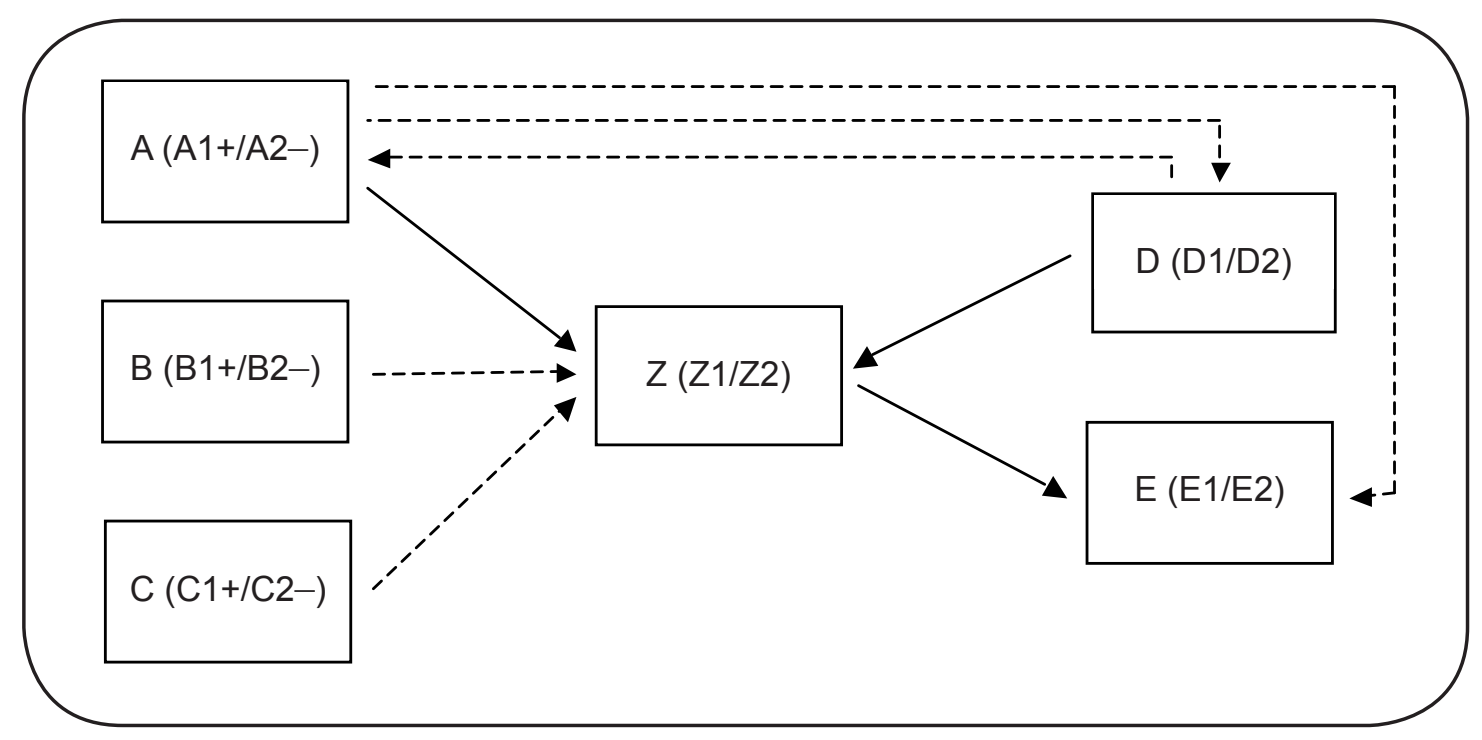

Figura 2. Diagrama das relações ensinadas e testadas. As setas contínuas representam discriminações condicionais ensinadas, e as setas tracejadas, as relações condicionais testadas. As letras representativas dos estímulos separadas por uma barra indicam discriminações simples ensinadas (quanto estiverem presentes os sinais + e - ) e relações testadas (sem a presença dos sinais).

$\mathrm{Na}$ sexta tentativa eram apresentados os dois estímulos $\left(\mathrm{S}^{+}\right.$e $\left.\mathrm{S}^{-}\right)$simultaneamente, respostas corretas eram novamente consequenciadas pelas estrelinhas e, em seguida, era apresentada a figura de um palhaço acompanhada da instrução gravada: "Olha, as estrelinhas! Você acertou!” Respostas incorretas eram seguidas pela apresentação de uma tela preta durante dois segundos e, em seguida, pela apresentação da figura do palhaço seguida da instrução: "Ih... Cadê as estrelinhas? Ah, que pena..." Em caso de acerto na sexta tentativa, a experimentadora sugeria, na tentativa seguinte, que a criança clicasse na outra figura, ou então ela própria executava a resposta, dizendo: "E se a gente apertar no outro, o que acontece? Vamos ver?" Nas demais tentativas era apresentado o par de estímulos, e as consequências programadas eram as estrelas e os sons em caso de acerto; em caso de erro, a tela preta. Essa sessão era realizada uma vez.

A sessão 2 do Passo 1 era similar à primeira, exceto que eram apresentadas 20 tentativas; nas cinco tentativas iniciais eram apresentados apenas o $\mathrm{S}^{+}(\mathrm{K} 1)$ e as mesmas instruções gravadas. $\mathrm{Na}$ sessão 3, os estímulos $\mathrm{K} 1$ e $\mathrm{K} 2$ ( $\mathrm{S}^{+}$ e $\mathrm{S}^{-}$) eram sempre apresentados simultaneamente em 20 tentativas, sem quaisquer instruções gravadas. Nas sessões 4 e 5 , com 25 e 30 tentativas, respectivamente, eram apresentados novos pares de estímulos (V1/V2 e W1/W2) sem instruções, e as consequências eram as previstas para acerto ou erro. $\mathrm{O}$ critério de ensino para as sessões 2 a 5 era de no máximo um erro por sessão.

A partir da sessão 2, além das consequências apresentadas na tela do computador, as respostas corretas eram também consequenciadas com fichas plásticas colocadas pela ex- 
perimentadora em um copo de plástico transparente que permanecia ao lado da tela. Eram fornecidas instruções e consequências de acordo com a seguinte regra: a criança poderia escolher dois jogos para brincar após atingir o critério - "ao encher o copo de fichas" ou apenas um jogo (essa "regra" era descrita e aplicada ao longo de todo o procedimento). Consequências sociais contingentes ao desempenho das crianças também eram fornecidas pela experimentadora (e.g., elogios, sorrisos) durante e após as sessões no computador.

O Passo 2 do pré-treino era composto por tarefas de discriminação condicional visual-visual semiarbitrária, em que os estímulos empregados como modelo eram quadrados coloridos (X1 e X2), e os estímulos de comparação eram "bonecos" (Y1 e Y2) nas mesmas cores, azul e vermelho. A primeira sessão era composta por 30 tentativas, e a instrução inicial simultânea à primeira tentativa era a mesma da fase anterior. As 16 tentativas iniciais eram apresentadas em quatro blocos de quatro tentativas, dois blocos com cada modelo (X1 e X2). Nas duas primeiras tentativas consecutivas com cada modelo, era apresentado apenas o $\mathrm{S}^{+}$(Y1 ou Y2, respectivamente). Nas tentativas seguintes, eram apresentados simultaneamente os dois estímulos de comparação. Nas seis próximas tentativas, os modelos eram apresentados em três tentativas consecutivas, e, por fim, as oito últimas tentativas eram apresentadas em sequência semialeatória de uma, duas ou três tentativas consecutivas de cada modelo.

A segunda sessão era composta por 30 tentativas distribuídas em sequência randômica com os estímulos modelo X1 e X2 (15 tentativas de cada modelo) e os dois estímulos de comparação (Y1 e Y2).

\section{Ensino de discriminações simples separadas} (A1/A2, B1/B2 e C1/C2)

O objetivo desta fase era o ensino da linha de base inicial de discriminações simples. Inicialmente, era ensinada a discriminação com o primeiro par de estímulos (A1+/ A2-), em sessões de 30 tentativas (em todas as tentativas era apresentado o par de estímulos), até o critério de ensino. A seguir, duas novas discriminações (B1+/B2-; C1+/C2-) eram ensinadas separadamente, de acordo com o mesmo procedimento.

3. Discriminações simples intercaladas $(A 1 / A 2$, $B 1 / B 2$ e $C 1 / C 2$ )

Nesta fase, os três pares de estímulos eram apresentados em uma mesma sessão de 30 tentativas. Inicialmente, eram apresentadas sessões com blocos de 10 tentativas consecutivas com cada par; seguidas por sessões com blocos de cinco tentativas; blocos de três tentativas de cada par; e, por fim, a distribuição de tentativas era randômica. As sessões com apresentação do mesmo número de tentativas consecutivas com cada discriminação eram realizadas até que fosse atingido o critério de no máximo dois erros por sessão (e não mais que um erro por par de estímulos).

\section{Ensino de relações condicionais $(A Z)$}

Nesta fase, eram ensinadas relações condicionais entre os estímulos da primeira discriminação simples (A1+, A2-), empregados como modelos, e um novo conjunto de estímulos (Z), empregados como estímulos de comparação, por meio do procedimento de emparelhamento com o modelo. As crianças eram ensinadas a relacionar o estímulo A1, com função de $\mathrm{S}^{+}$na linha de 
base de discriminações simples, ao estímulo Z1, e o estímulo A2, com função de $\mathrm{S}^{-}$, ao estímulo Z2.

O treino blocado (Saunders \& Spradlin, 1989, 1990, 1993) foi programado partindo da apresentação de blocos de tentativas consecutivas de um mesmo estímulo modelo e reduzindo gradualmente o número de tentativas consecutivas até a apresentação randômica. As sessões com a apresentação de um mesmo número de tentativas consecutivas com cada modelo eram realizadas até o alcance do critério, nesta e nas demais fases de treino blocado. Na primeira sessão (sessão 0), os modelos (A1 e A2) eram apresentados em blocos de oito, quatro e três tentativas consecutivas com cada modelo. A instrução inicial simultânea à primeira tentativa era: "Olha, agora a figura está no meio! Você pode clicar para ver o que vai aparecer." Nas duas primeiras tentativas com cada modelo, era apresentado apenas o $\mathrm{S}^{+}$, e nas demais eram apresentados os dois estímulos de comparação.

$\mathrm{Na}$ sessão 1, eram apresentados blocos de quatro tentativas consecutivas com cada modelo (A1 ou A2), seguidas de blocos de três tentativas consecutivas e, por fim, quatro tentativas em sequência semialeatória de uma, duas ou três tentativas de cada modelo. Apenas nas duas primeiras tentativas da sessão (com o modelo A1) era apresentado somente o $^{+}$(Z1). Nas demais tentativas, eram apresentados sempre os dois estímulos de comparação (Z1 e Z2). Caso a criança realizasse essa sessão mais de uma vez, a estrutura de tentativas era a mesma, embora a sessão fosse iniciada ora com o modelo A1 ora com A2.

A sessão 2 era composta por 30 tentativas distribuídas randomicamente, metade com cada modelo.
5. Linha de base mista $(A 1 / A 2, B 1 / B 2, C 1)$ C2 е $A Z$ )

Nesta fase, as duas linhas de base ensinadas até então (discriminações simples:A1/A2;B1/ B2; C1/C2; e discriminações condicionais: A1Z1; A2Z2) eram apresentadas em uma mesma sessão de 30 tentativas. Inicialmente, eram apresentadas sessões com blocos de 15 tentativas consecutivas de cada linha de base; seguidas por sessões com blocos de sete ou oito tentativas; e, então, sessões com blocos de cinco tentativas consecutivas de cada linha de base. Em seguida, seis tentativas de cada linha de base (simples e condicional) eram apresentadas em uma mesma sessão em sequência randômica e com reforço contínuo.

Modelagem ao esquema de reforçamento intermitente. As sessões desta fase foram planejadas para estabelecer diminuição gradual do reforçamento. Inicialmente, 20 das 30 tentativas da sessão eram reforçadas (quatro de cada relação) e, a seguir, 15 das 30 tentativas eram reforçadas (três de cada relação). As sessões com cada razão eram repetidas até o critério de ensino. Por fim, nas sessões de linha de base antecedentes aos testes, 10 tentativas eram reforçadas (duas de cada relação).

Ao início de cada sessão em esquema intermitente (incluindo as sessões de teste, descritas a seguir), era apresentada a seguinte instrução na presença da figura de um palhaço "falante": "Preste muita atenção! Agora as estrelinhas só vão aparecer algumas vezes, mas você vai continuar ganhando as fichas. Vamos começar?"

\section{Teste de emergência de discriminação simples} (Z1/Z2)

O objetivo deste teste era verificar se, diante de uma tarefa de discriminação simples, os participantes escolheriam o estímulo Z1 e não 
Z2, considerando a história de reforçamento em que o estímulo Z1 foi relacionado ao A1, que, por sua vez, exercia função de $\mathrm{S}^{+}$na linha de base inicial de discriminações simples. A sessão de teste era composta por 30 tentativas, sendo oito tentativas de teste em extinção (discriminação simples Z1/Z2) intercaladas com 22 tentativas de linha de base: quatro tentativas de cada relação (A1/A2; B1/B2; C1/C2; A1Z1; A2Z2) e duas tentativas do conjunto $\mathrm{XY}$ para completar o número de 30 tentativas por sessão (10 tentativas de linha de base eram reforçadas, duas de cada tipo). O critério de finalização desta e das demais fases de teste era a realização de três sessões consecutivas.

7. Retorno à linha de base mista $(A 1 / A 2, B 1 /$ B2, C1/C2 e AZ)

Nesta fase, era retomada a linha de base mista em esquema de reforçamento intermitente antes da aplicação dos testes de discriminação condicional.

8. Teste de emergência de discriminações condicionais (BZ e CZ)

Neste teste, era avaliada a emergência de relações não ensinadas entre os estímulos dos conjuntos $\mathrm{B}$ e $\mathrm{C}$ e os do conjunto $\mathrm{Z}$. O teste era constituído por quatro tentativas de teste em extinção de cada relação BZ e CZ (duas tentativas com cada um dos modelos B1, B2, $\mathrm{C} 1$ e C2). Essas sondas eram intercaladas com 22 tentativas de linha de base (10 tentativas reforçadas). Em caso de emergência das relações (porcentagem de respostas consistentes acima de 90), o participante era exposto às fases subsequentes do procedimento. Caso fossem apresentados indícios de emergência das relações (porcentagem de respostas consistentes entre 75 e 85) ou não fosse de- monstrada emergência dessas relações (porcentagens abaixo de 75), a linha de base seria retreinada (uma das relações, BZ ou CZ, era ensinada) e os testes seriam repetidos.

Encerrada a primeira etapa do procedimento (fases 1 a 8), os participantes eram expostos à Etapa 2 (fases 9 a 13), que teve como objetivo verificar se estímulos relacionados condicionalmente a estímulos das classes funcionais previamente estabelecidas poderiam ser incluídos nessas classes, e se as classes funcionais poderiam funcionar, também, como classes de equivalência.

\section{Ensino de novas relações condicionais ( $\mathrm{DZ}$ e $Z \mathrm{ZE})$}

Nesta fase do procedimento (início da Etapa 2), eram ensinadas relações condicionais entre novos conjuntos de estímulos (D e E) e o conjunto $Z$, para se verificar, posteriormente, se esses estímulos seriam incluídos nas classes funcionais previamente estabelecidas (por meio de testes de discriminação simples). As novas relações ensinadas foram DZ e ZE (em que, pela primeira vez, os estímulos do conjunto $Z$ exerceram função de modelo) para verificar possíveis efeitos da "direção" do treino. As relações foram ensinadas separadamente, como realizado no ensino da relação AZ (Fase 4), exceto que não eram apresentadas instruções no primeiro bloco.

\section{Linha de base mista $(A 1 / A 2, B 1 / B 2, C 1 /$ C2, Z1/Z2, AZ, BZ, CZ, DZ e ZE)}

Esta linha de base era composta por tentativas de discriminação simples e condicional ensinadas diretamente e pelas relações apenas avaliadas durante os testes anteriores. Eram apresentadas tentativas de discriminação simples (pares A1/A2, B1/B2, C1/C2, Z1/Z2) e condicional (AZ, BZ, CZ, DZ e ZE). 
Inicialmente, as relações DZ e ZE eram apresentadas em blocos de 15 tentativas consecutivas cada, em uma sessão de 30 tentativas. As relações AZ, BZ e CZ eram apresentadas em blocos de 10 tentativas consecutivas cada, em outra sessão de 30 tentativas. Cada sessão era realizada até o critério. Depois disso, os cinco tipos de relações condicionais eram apresentados em uma mesma sessão em blocos de seis tentativas consecutivas de cada relação condicional. A seguir, foram programadas sessões compostas pelas discriminações simples e condicionais. Inicialmente, era realizada uma sessão com blocos de 15 tentativas consecutivas de cada discriminação (em uma mesma sessão de 30 tentativas, até o critério), seguida por outra sessão de 30 tentativas em que eram apresentados blocos de sete ou oito tentativas de discriminações simples e condicionais.

Por fim, as discriminações simples e condicionais eram apresentadas em sequência randômica na sessão. Eram apresentadas 20 tentativas de discriminação condicional (quatro de cada tipo de relação, duas com cada modelo) e oito tentativas de discriminação simples (duas de cada). Para completar a soma de 30, eram apresentadas, também, duas tentativas "fáceis", com novos estímulos do conjunto XY (X3Y3 e X4Y4, quadrados e bonecos nas cores amarelo e marrom). Inicialmente, as respostas eram consequenciadas em esquema de reforçamento contínuo e, após alcance do critério, metade das tentativas era reforçada (uma de cada tentativa de linha de base e uma da relação XY). O critério era de $96,6 \%$ de acertos (inclusive nas sessões com reforçamento intermitente antecedentes aos testes, para evitar exposição excessiva e fadiga da tarefa, o que poderia deteriorar o desempenho das crianças).
11. Teste de formação de classes funcionais (discriminações simples D1/D2 e E1/E2)

O objetivo deste teste era verificar se os novos estímulos relacionados condicionalmente a estímulos das classes funcionais seriam incluídos nas classes. As sessões tinham oito tentativas de teste em extinção (quatro tentativas de cada discriminação simples D1/ D2 e E1/E2), 18 tentativas de linha de base (uma tentativa de discriminação condicional com cada modelo e duas tentativas de cada discriminação simples) e quatro tentativas com os estímulos XY. Dentre as tentativas de linha de base, 15 eram reforçadas, sendo 10 de discriminação condicional, quatro de discriminação simples e uma das relações XY.

\section{Retorno à linha de base mista $(A 1 / A 2, B 1 / B 2$, C1/C2, Z1/Z2, AZ, BZ, CZ, DZ e ZE)}

Nesta fase, era retomada a linha de base mista em reforçamento contínuo, seguida por reforçamento intermitente, como preparação para os testes subsequentes, até o critério de $96,6 \%$ de acertos.

\section{Teste de relações emergentes (discriminações condicionais $A D, D A$ e $A E$ )}

Este teste funcionava como medida adicional de formação de classes funcionais, avaliando se os membros das classes funcionais (classe dos $\mathrm{S}^{+}$versus classe dos $\mathrm{S}^{-}$) seriam emparelhados entre si.Além disso, permitia avaliar se as classes funcionais implicariam classes de equivalência ao se testarem relações emergentes entre os membros das classes funcionais (relações $\mathrm{AD}, \mathrm{DA}$ e $\mathrm{AE})$. A sessão era composta por 18 tentativas de linha base mista (14 das tentativas reforçadas) e 12 tentativas de teste em extinção (quatro tentativas de cada uma das relações AD, DA e AE, duas com cada modelo). 


\section{Resultados}

O objetivo do presente estudo foi avaliar os efeitos de um procedimento de ensino sobre a aquisição de discriminações simples e condicionais intercaladas, sobre a transferência de função de estímulos e sobre a formação de classes funcionais e classes de equivalência. Os resultados da aprendizagem das linhas de base das discriminações simples e condicionais (separadas ou intercaladas) e dos testes foram analisados em termos do número de sessões realizadas por cada participante até que fosse atingido o critério e do número de erros apresentados em cada fase experimental. Os resultados nas sondas também foram analisados como porcentagem de respostas consistentes com as funções de estímulos estabelecidas na fase de ensino, como base para interpretar a emergência ou não de desempenhos novos.

As seis crianças que participaram do estudo aprenderam as discriminações simples e condicionais e também apresentaram desempenhos acurados nas fases de linha de base mista, em que eram apresentadas tentativas misturadas de discriminação simples e condicional. Na primeira etapa do procedimento, quatro participantes (Nanda, Bebel, Juca e Fábio) foram expostos ao ensino de três discriminações simples (A1/A2, B1/B2 e C1/ C2) e das discriminações condicionais (AZ), enquanto outros dois participantes (Tuco e Mili) aprenderam duas discriminações simples (A1/A2 e B1/B2) e as relações condicionais (AZ). A seguir, foram realizados testes de discriminação simples $\mathrm{Z1} / \mathrm{Z} 2$ para as seis crianças, e de discriminações condicionais $\mathrm{BZ}$ e CZ para as crianças que aprenderam três discriminações simples (Nanda, Bebel,
Juca e Fábio) e apenas das relações BZ no caso das crianças que aprenderam apenas duas discriminações simples (Tuco e Mili). A partir dos resultados do teste de discriminações condicionais, era avaliada a necessidade de treino de novas relações condicionais e reteste. Assim, de acordo com os dados, alguns participantes foram expostos a essas condições adicionais. Em relação à segunda etapa do procedimento, dois participantes (Juca e Fábio), que aprenderam inicialmente três discriminações simples e as relações condicionais, foram expostos ao ensino de novas discriminações condicionais (DZ e ZE), testes de formação de classes funcionais (discriminações simples, D1/D2 e E1/E2) e testes de relações emergentes (discriminações condicionais $\mathrm{AD}, \mathrm{DA}$ e AE). A Tabela 3 apresenta o número de sessões realizadas até que fosse atingido o critério em cada uma das fases de ensino e teste, e o número de erros nas diferentes fases experimentais. Na primeira etapa do procedimento, o número de sessões realizadas até critério foi menor, ou seja, mais próximo do mínimo previsto, no ensino das discriminações simples separadas do que no ensino de discriminações simples intercaladas. $\mathrm{Na}$ fase de ensino de discriminações simples separadas, por exemplo, as crianças expostas ao ensino de três discriminações aprenderam a tarefa em três, quatro ou cinco sessões, e as crianças expostas ao ensino de duas discriminações realizaram de duas a quatro sessões. Assim, todas as crianças aprenderam cada uma das discriminações em uma ou duas sessões e apresentaram poucos erros (os participantes apresentaram de um a quatro erros nessa fase, exceto Nanda, que apresentou sete erros). Em relação à fase de discriminações intercaladas, as seis crianças realizaram um 
total de quatro a oito sessões (sendo o número mínimo previsto igual a quatro). A participante Bebel foi exposta ao retreino das discriminações com estímulos novos e, a seguir, às demais fases experimentais por apresentar número crescente de erros no ensino das discriminações simples intercaladas em sequência randômica. Os dados dessa participante apresentados na Tabela 3 são do retreino com novos pares (ocasião em que apresentou apenas três erros). Os participantes Juca e Fábio aprenderam as discriminações intercaladas sem erros, e os demais participantes (Mili, Tuco e Nanda) apresentaram de seis a 12 erros. No ensino da discriminação condicional (AZ), a participante Nanda foi exposta a apenas duas sessões de ensino por ser a primeira participante exposta a essa fase. Após exposição à sessão 1 , foi programada uma sessão inicial de ensino (sessão 0) em que o número de tentativas consecutivas com cada modelo (A1 ou A2) era maior, com o objetivo de minimizar a ocorrência de erros (considerando que Nanda apresentou nove erros em duas sessões). Outras quatro crianças (Bebel, Fábio Tuco e Mili) realizaram de três a seis sessões até atingir o critério, e apenas uma criança (Juca) realizou 12 sessões, sendo o mínimo previsto três sessões. Os participantes Bebel e Fábio apresentaram apenas dois erros nessa fase; os participantes Tuco e Mili, 11 erros; e apenas Juca (exposto a um número maior de sessões) apresentou 27 erros. Ao longo do procedimento, a partir do ensino das linhas de base mistas, o número de sessões até o critério passou a ser mais próximo do mínimo previsto para todos os participantes. Nessa fase, o número mínimo de sessões previstas era diferente para as crianças expostas ao ensino de três ou duas discriminações simples (oito ou cinco sessões, respectivamente). O participante Fábio, por exemplo, realizou o número mínimo de sessões em diversas fases experimentais e não foi exposto às fases graduais de ensino de relações condicionais (BZ ou CZ) e, sim, diretamente à fase de mistura de linha de base em treino randômico (por isso realizou número menor de sessões do que o previsto). Em relação ao número de erros, na linha de base mista, observa-se diminuição do número de erros em relação às duas fases anteriores (aprendizagem das discriminações simples intercaladas e das relações AZ) para os participantes Juca, Tuco e Mili (enquanto, para os demais participantes, o número de erros foi próximo ou superior àquele apresentado nas fases anteriores).

Os dados dos testes da primeira etapa do procedimento, em forma de porcentagem de respostas consistentes com as funções de estímulo estabelecidas na fase de ensino, nas tentativas de sonda para cada uma das relações, estão apresentados na Figura 3. A figura apresenta a porcentagem de respostas (eixo Y) em cada uma das relações testadas (eixo $\mathrm{X}$ ), na sequência em que os testes foram realizados para cada participante. As barras pretas representam a porcentagem de respostas sob controle de estímulos da classe 1 (Z1), e as barras cinza, respostas em relação a estímulos da classe 2 (Z2). As barras à esquerda da linha tracejada representam os resultados de teste das relações, e as barras à direita da linha tracejada, os resultados de reteste. Em relação ao teste de discriminação simples Z1/Z2, realizado por todos os participantes, as porcentagens de acertos foram acima de 90\% para quatro crianças (Mili, Bebel, Juca e Fábio) e de 83,3 e 75\% para Tuco e Nanda, respectivamente. 
Tabela 3

Número de sessões realizadas até o critério (Ss) e número de erros (E) nas diferentes fases experimentais (a parte sombreada em cinza representa as fases de retreino e reteste.

Os dados da participante Bebel são referentes ao ensino com novos estímulos)

\begin{tabular}{|c|c|c|c|c|c|c|c|c|c|c|c|c|}
\hline \multirow{3}{*}{$\begin{array}{c}\text { Fases } \\
\text { Etapa } 1\end{array}$} & \multicolumn{12}{|c|}{ Participantes } \\
\hline & \multicolumn{2}{|c|}{ Nanda } & \multicolumn{2}{|c|}{ Bebel } & \multicolumn{2}{|c|}{ Juca } & \multicolumn{2}{|c|}{ Fábio } & \multicolumn{2}{|c|}{ Tuco } & \multicolumn{2}{|c|}{ Mili } \\
\hline & Ss & $\mathrm{E}$ & Ss & $\mathrm{E}$ & Ss & $\mathrm{E}$ & Ss & $\mathrm{E}$ & Ss & $\mathrm{E}$ & Ss & $\mathrm{E}$ \\
\hline \multirow[t]{2}{*}{ 1) Pré-treino } & 9 & 6 & 9 & 9 & 13 & 8 & 10 & 5 & 13 & 11 & 14 & 11 \\
\hline & \multicolumn{12}{|c|}{ Linha de base } \\
\hline $\begin{array}{l}\text { 2) Linhas de base DS } \\
\text { separadas (A, B e C ou } \\
\text { A e B) }\end{array}$ & 5 & 7 & 4 & 4 & 4 & 4 & 3 & 1 & 2 & 2 & 4 & 4 \\
\hline $\begin{array}{l}\text { 3) Linhas de base DS } \\
\text { alternadas (A, B e C ou } \\
\text { A e B) }\end{array}$ & 6 & 12 & 5 & 3 & 4 & 0 & 4 & 0 & 8 & 10 & 6 & 6 \\
\hline $\begin{array}{l}\text { 4) Linha de base DC } \\
\text { (AZ) }\end{array}$ & 2 & 9 & 3 & 2 & 12 & 27 & 4 & 2 & 6 & 11 & 6 & 11 \\
\hline $\begin{array}{l}\text { 5) Linha de base mista } \\
\text { (A, B, C e AZ ou A, B } \\
\text { e AZ) }\end{array}$ & 12 & 16 & 10 & 3 & 10 & 8 & 9 & 6 & 5 & 2 & 6 & 5 \\
\hline Total & 25 & 44 & 22 & 12 & 30 & 39 & 20 & 9 & 21 & 25 & 22 & 26 \\
\hline \multirow[t]{2}{*}{ Erros/sessão } & \multicolumn{2}{|c|}{1,76} & \multicolumn{2}{|c|}{0,54} & \multicolumn{2}{|c|}{1,3} & \multicolumn{2}{|c|}{0,45} & \multicolumn{2}{|c|}{1,19} & \multicolumn{2}{|c|}{1,18} \\
\hline & \multicolumn{12}{|c|}{ Testes } \\
\hline 6) Teste DS (Z1/Z2) & 3 & 8 & 3 & 2 & 3 & 3 & 3 & 0 & 3 & 2 & 3 & 4 \\
\hline $\begin{array}{l}\text { 7) Retorno à linha de } \\
\text { base mista }\end{array}$ & 5 & 4 & 2 & 0 & 5 & 5 & 2 & 0 & 3 & 1 & 2 & 0 \\
\hline 8) Teste DC (BZ) & - & - & - & - & - & - & - & - & 2 & 3 & 4 & 9 \\
\hline 8) Teste DC (BZ e CZ) & 3 & 13 & 3 & 11 & 3 & 17 & 3 & 12 & - & - & - & - \\
\hline
\end{tabular}

\section{Retreino da linha base}

\begin{tabular}{lcccccccccccc}
\hline $\begin{array}{l}\text { Linha de base DC }(\mathrm{BZ} \\
\text { ou CZ) }\end{array}$ & 4 & 3 & 4 & 4 & 4 & 7 & - & - & - & - & - & - \\
$\begin{array}{l}\text { Linha de base DC } \\
\text { (AZ + BZ ou CZ) }\end{array}$ & 3 & 2 & 3 & 0 & 3 & 1 & - & - & - & - & - & - \\
$\begin{array}{l}\text { Linha de base mista (A, } \\
\text { B, C, AZ + BZ ou CZ) }\end{array}$ & 10 & 6 & 8 & 1 & 8 & 2 & 4 & 2 & - & - & - & - \\
\hline Total & 17 & 11 & 15 & 5 & 15 & 10 & 4 & 2 & - & - & - & - \\
\hline Erros/sessão & 0,65 & 0,33 & 0,67 & 0,50 & - & & - \\
\hline Reteste DC (CZ ou BZ) & 3 & 10 & 3 & 1 & $2 / 3$ & 5 & 3 & 4 & 4 & 9 & 3 & 4 \\
\hline Total na Etapa 1 & 65 & 96 & 57 & 40 & 73 & 87 & $45^{\star}$ & 32 & 46 & 51 & 48 & 50 \\
\hline
\end{tabular}




\begin{tabular}{|c|c|c|c|c|c|c|c|c|c|c|c|c|}
\hline \multirow{3}{*}{$\begin{array}{c}\text { Fases } \\
\text { Etapa } 2\end{array}$} & \multicolumn{12}{|c|}{ Participantes } \\
\hline & \multicolumn{2}{|c|}{ Nanda } & \multicolumn{2}{|c|}{ Bebel } & \multicolumn{2}{|c|}{ Juca } & \multicolumn{2}{|c|}{ Fábio } & \multicolumn{2}{|c|}{ Tuco } & \multicolumn{2}{|c|}{ Mili } \\
\hline & Ss & $\mathrm{E}$ & Ss & $\mathrm{E}$ & Ss & $\mathrm{E}$ & Ss & $\mathrm{E}$ & Ss & $\mathrm{E}$ & Ss & $\mathrm{E}$ \\
\hline $\begin{array}{l}\text { 9) Linha de base DC } \\
\text { (DZ, ZE) }\end{array}$ & - & - & - & - & 11 & 11 & 9 & 4 & - & - & - & - \\
\hline $\begin{array}{l}\text { 10) Linha de base } \\
\text { mista (AZ, BZ, CZ, } \\
\text { DZ, ZE + A, B, C, Z) }\end{array}$ & - & - & - & - & 8 & 13 & 8 & 9 & - & - & - & - \\
\hline $\begin{array}{l}\text { 11) Teste DS } \\
\text { (D1/D2 e E1/E2) }\end{array}$ & - & - & - & - & 3 & 8 & 3 & 6 & - & - & - & - \\
\hline $\begin{array}{l}\text { 12) Retorno linha } \\
\text { de base mista }\end{array}$ & - & - & - & - & 3 & 5 & 3 & 3 & - & - & - & - \\
\hline $\begin{array}{l}\text { 13) Teste DC } \\
\text { (AD, DA e AE) }\end{array}$ & - & - & - & - & 3 & 2 & 3 & 6 & - & - & - & - \\
\hline Total na Etapa 2 & - & - & - & - & 28 & 39 & 26 & 28 & - & - & - & - \\
\hline
\end{tabular}

* O mínimo de sessões previstas para Fábio era de 43 (por não ter sido exposto ao ensino de BZ).

Nos testes de discriminações condicionais BZ e CZ, a porcentagem de respostas consistentes com o ensino variou de 25 a $100 \%$ para as relações testadas. Considerando-se o desempenho dos participantes que aprenderam três discriminações simples, o participante Fábio apresentou 100\% de respostas consistentes com o ensino direto para as relações $\mathrm{BZ}$, o que indica emergência das relações. No caso das relações CZ, o participante apresentou $100 \%$ de respostas consistentes em tentativas em que o estímulo Z1 era positivo (C1 era modelo); entretanto, em tentativas em que o estímulo Z2 era positivo (C2 era modelo), observa-se porcentagem igual a zero (ou seja, o participante novamente emitiu todas as respostas diante do comparação Z1, que, nesse caso, era $\mathrm{S}^{-}$). Os participantes Bebel e Juca apresentaram desempenhos similares no teste das relações BZ e CZ: porcentagens elevadas de respostas consistentes diante de Z1 em tentativas em que estímulos do conjunto 1 eram modelo (B1 ou C1), e porcentagens baixas ou iguais a zero em tentativas em que o estímulo Z2 era o comparação correto. A participante Nanda apresentou porcentagem de respostas consistentes próxima a 25\% para as relações BZ e indícios de emergência das relações CZ, com porcentagem de respostas consistentes de $100 \%$ em tentativas em que Z1 era positivo e de $66,6 \%$ em tentativas em que $\mathrm{Z} 2$ era positivo, ou seja, porcentagem de respostas mais elevada em relação a Z1. No teste $B Z$, na condição de ensino de duas discriminações simples (figuras sombreadas), a que foram expostos dois participantes, as porcentagens de respostas consistentes foram de $75 \%$ para Tuco e aproximadamente 50\% para Mili.

Diante dos resultados do teste de discriminações condicionais, em que apenas um dos participantes apresentou emergência das 


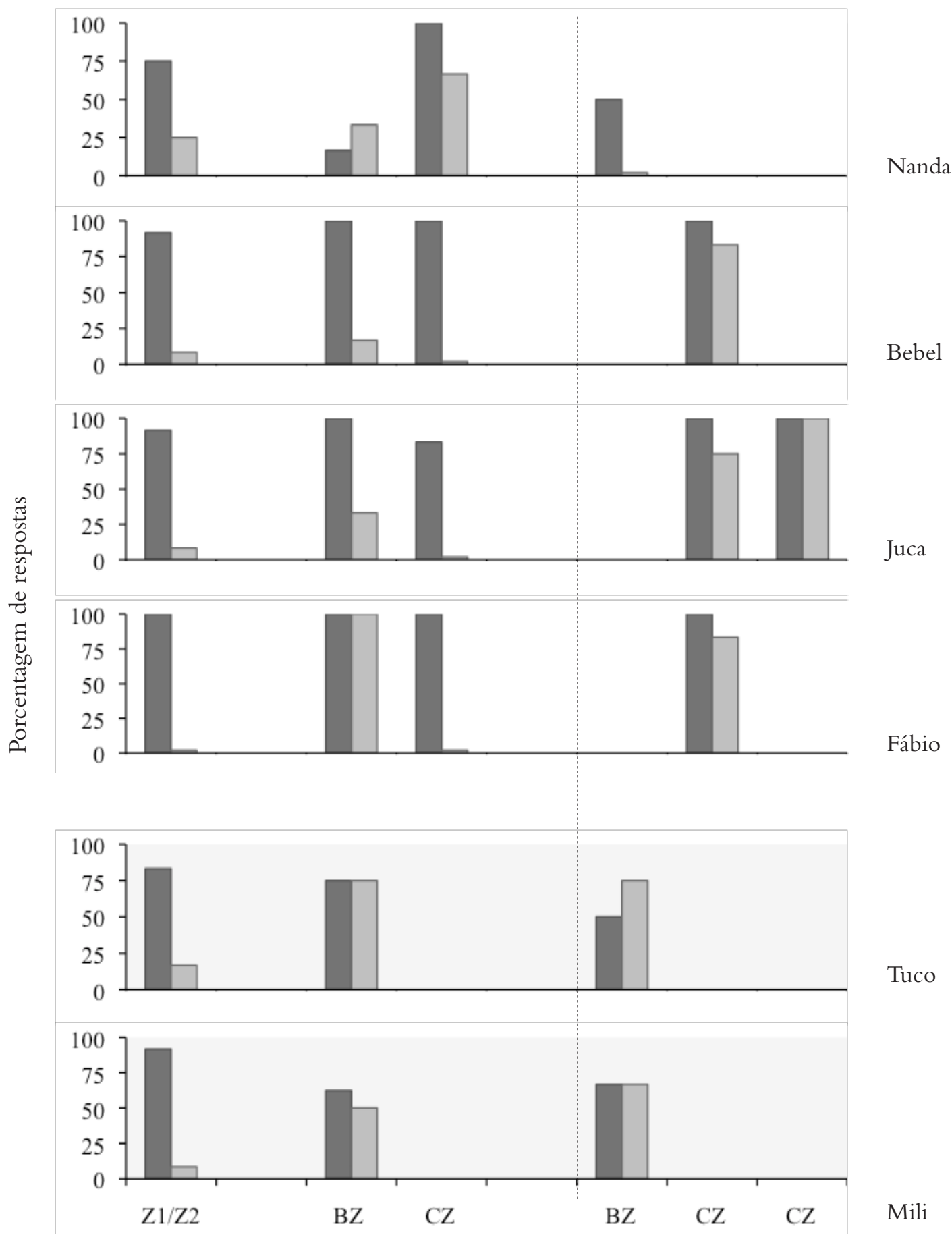

Figura 3. Porcentagem de respostas consistentes (com as funções de estímulo estabelecidas no treino) em tentativas de sonda dos blocos de teste de discriminação simples Z1/Z2, teste e reteste (barras à direita da linha tracejada) de discriminação condicional BZ e CZ/BZ ou CZ, de acordo com a sequência aplicada para cada participante. As barras pretas representam respostas sob controle de estímulos da classe 1 (Z1), e as barras cinza, respostas sob controle da classe 2 (Z2). As figuras sombreadas indicam os participantes expostos ao ensino de duas discriminações simples. 
relações BZ (Fábio) e outros dois participantes demonstraram indícios de emergência das relações BZ e CZ (Tuco e Nanda, respectivamente) foram realizadas etapas adicionais de reteste. No caso do participante Fábio, as relações emergentes BZ foram incorporadas à linha de base mista anterior e foi realizado o reteste das relações CZ. Os resultados, dessa vez, foram positivos, indicando emergência atrasada dessas relações $(100 \%$ e 83,3\% de respostas consistentes em tentativas com os modelos $\mathrm{C} 1$ e $\mathrm{C} 2$, respectivamente). Os participantes Bebel e Juca foram expostos ao treino das relações BZ (de acordo com os mesmos procedimentos e critérios do treino das discriminações AZ), que, em seguida, foram incorporadas à linha de base mista anterior e reteste das relações CZ. Os resultados do reteste foram positivos, indicando a emergência atrasada das relações CZ para Bebel (100\% e $83,3 \%$ de respostas consistentes em tentativas com os modelos C1 e C2) e Juca (100\% e $75 \%$ de respostas consistentes em tentativas com os modelos C1 e C2). Juca, entretanto, foi exposto a apenas duas sessões de teste (e não a três sessões, como previsto), porque faltou à creche nos dias subsequentes de coleta. O reteste das relações CZ foi repetido e aplicado por três sessões consecutivas, ocasião em que Juca apresentou 100\% de respostas consistentes. A participante Nanda foi exposta ao treino das relações $\mathrm{CZ}$ e reteste das relações BZ. No reteste, a porcentagem de respostas consistentes manteve-se baixa (similar à do teste inicial). Os participantes Tuco e Mili, expostos ao ensino de duas discriminações simples e das relações condicionais $\mathrm{AZ}$, foram expostos apenas ao retreino da linha de base mista e reteste das relações BZ. No reteste, a porcentagem de respostas consistentes com a linha de base foi igual ou próxima a $66,6 \%$ para cada criança.

Os participantes Juca e Fábio, que apresentaram resultados positivos nos testes da Etapa 1 do procedimento e mantiveram-se engajados nas tarefas experimentais, foram expostos à Etapa 2 (ensino de novas discriminações condicionais DZ e ZE, e testes de discriminação simples e condicionais, ver Tabela 3). Os participantes aprenderam as discriminações condicionais e as linhas de base mista em número de sessões próximo ao mínimo previsto. Em relação aos erros, o participante Juca aprendeu as novas discriminações condicionais com um número menor de erros (11) em comparação à aprendizagem das relações AZ (27). Fábio apresentou poucos erros na aprendizagem das duas novas relações (apenas quatro), tal como na aprendizagem das relações AZ.

Os dados dos testes da segunda etapa do procedimento (testes de discriminação simples D1/D2 e E1/E2, e de discriminações condicionais $\mathrm{AD}, \mathrm{DA}$ e $\mathrm{AE}$ ), a que foram expostos os dois participantes, estão apresentados na Figura 4, no mesmo formato da Figura 3. A linha de base mista antecedente e intercalada às sessões de teste era composta por todas as tentativas de discriminações simples e condicionais ensinadas diretamente e avaliadas nos testes anteriores. As porcentagens de respostas consistentes com o ensino direto nos testes de discriminação simples D1/D2 e E1/E2 foram de 87,5\% e 68,7\%, para Juca; e de $91,6 \%$ e $83,3 \%$, para Fábio. No teste de relações emergentes entre membros das classes funcionais, em que foram testadas as relações condicionais AD, DA e AE, o participante Juca apresentou $100 \%$ de respostas consistentes com o ensino para todas as rela- 
ções, e o participante Fábio, 100\% de respostas consistentes para as relações DA. Nas demais relações testadas ( $\mathrm{AD}$ e $\mathrm{AE}$ ), a porcentagem total de respostas consistentes com o treino foi de $100 \%$ em tentativas em que os estímulos de comparação do conjunto 1 funcionavam como $\mathrm{S}^{+}$, e de $66,6 \%$ em tentativas em que os estímulos de comparação do conjunto 2 eram $\mathrm{S}^{+}$(ou seja, porcentagens elevadas de respostas diante de estímulos de comparação do conjunto 1 , padrão similar ao observado anteriormente no desempenho do participante Fábio e de outros participantes nos testes de discriminações condicionais BZ e CZ).

\section{DISCUSSÃO}

O objetivo deste estudo foi avaliar os efeitos de um procedimento de ensino de discriminações simples e condicionais alternadas com testes de transferência de função (testes de discriminação simples e condicional), sobre a aquisição da linha de base, sobre a transferência de funções de estímulos e sobre a formação de classes (funcionais e de equivalência), em crianças pré-escolares. Resultados positivos em testes de transferência de função podem atestar a formação de classes funcionais e de equivalência, considerando que ocorre transferência de função entre estímulos de uma mesma classe (Sidman, 1994, 2000). O procedimento foi programado sem o emprego de reversões de discriminações simples e com a utilização de medidas independentes de teste para avaliar a formação de classes funcionais e classes de equivalência.

De forma geral, todas as crianças aprenderam as discriminações simples e condicionais

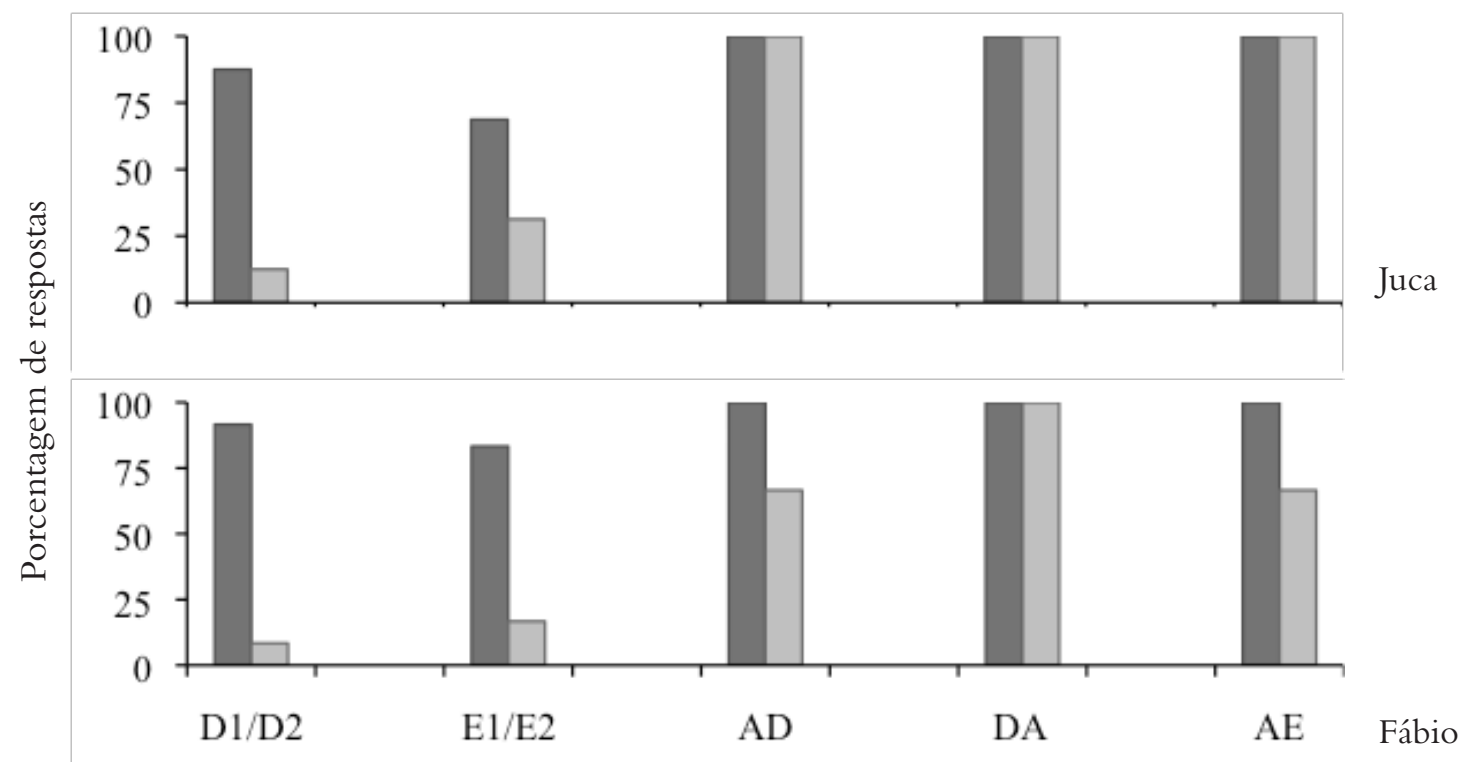

Figura 4. Porcentagem de respostas consistentes (com as funções de estímulo estabelecidas no treino) em tentativas de sonda dos blocos de testes da segunda etapa do procedimento; teste de discriminação simples D1/D2 e E1/E2 e teste de emparelhamento (discriminação condicional) $\mathrm{AD}, \mathrm{DA}$ e $\mathrm{AE}$ para os dois participantes expostos às respectivas fases. As barras pretas indicam respostas sob controle de estímulos da classe 1 (A1, D1 e E1), e as barras cinza, respostas diante de estímulos da classe 2 (A2, D2 e E2). 
separadas, mantiveram um desempenho acurado quando as discriminações foram intercaladas em uma mesma sessão e apresentaram um número relativamente pequeno de erros ao longo do procedimento. A aprendizagem das discriminações simples e condicionais era provável, em função da idade das crianças e de suas condições de desenvolvimento, e replica dados obtidos em outros estudos (Devany, Hayes, \& Nelson, 1986; Gil, Oliveira, de Sousa, \& Faleiros, 2006; Jordan, Pilgrim \& Galizio, 2001; Lionello-DeNolf et al., 2008; Lipkens, Hayes, \& Hayes, 1993; Pilgrim, Jackson, \& Galizio, 2000). Os resultados da aprendizagem das linhas de base mistas, com tentativas de discriminação simples e condicional misturadas em um mesmo bloco, complementam dados da literatura acerca da viabilidade de procedimentos nesse formato para a população de crianças pré-escolares (Boelens \& Smeets, 1990; Smeets \& Barnes, 1997).

Variáveis de procedimento são apontadas como extremamente relevantes para a investigação experimental com crianças pré-escolares e bebês, tanto para a manutenção dos participantes na situação experimental, quanto para favorecer a aprendizagem e minimizar a ocorrência de erros (Gil et al., 2006; Oliveira \& Gil, 2008; Pilgrim, Jackson, \& Galizio, 2000). Neste estudo, foi empregado um arranjo de contingências programadas para favorecer a aprendizagem, entre as quais as instruções; a apresentação de consequências diferenciais imediatas ou atrasadas para acertos e erros (consequências programadas no computador, brincadeira e reforçamento social, respectivamente); uso de procedimento de dica, em que era apresentado apenas o estímulo $\mathrm{S}^{+}$nas primeiras tentativas de ensino; emprego de treino blocado (Saunders \&
Spradlin, 1989, 1990, 1993); estabelecimento de contingências consistentes com as regras estabelecidas em sessão, em que a oportunidade da brincadeira era contingente ao desempenho da criança.

Considera-se que esses diversos aspectos de procedimento e o emprego de um treino de discriminações simples em que a função dos estímulos era sempre a mesma ao longo do experimento (sem a exposição a reversões das discriminações simples) podem ter contribuído para o estabelecimento das linhas de base consistentes e a ocorrência de um número relativamente pequeno de erros (ver Tabela 3). O treino realizado no presente estudo não produziu padrões deletérios de erros (e.g., Stoddard, de Rose, \& McIlvane, 1986) no desempenho dos participantes, diferentemente dos procedimentos de reversões repetidas de discriminações simples aplicados com essa mesma população (Canovas, 2010). Enquanto no presente estudo o número de erros por sessão na linha de base (Etapa 1) variou, entre participantes, de 0,45 a 1,71 (Tabela 3), os resultados de estudos que empregaram procedimentos de reversões repetidas de discriminações simples (simultâneas ou sucessivas) demonstram ocorrência de um número maior de erros. Essa comparação foi apresentada por Canovas (2010) a partir da reanálise dos resultados do Experimento 1 de Lionello-DeNolf et al. (2008). O número de erros por sessão apresentado pelos participantes expostos a esse procedimento variou de 1,4 a 2,8. No Experimento 1 de Canovas (2010), em que cinco crianças foram expostas ao procedimento de reversões de discriminações simples sucessivas, o número de erros por sessão variou de 1,2 a 4,1. Adicionalmente, neste estudo, 
nas fases seguintes de retreino da linha de base (Etapa 1), o número de erros por sessão foi ainda menor (variando de 0,33 a 0,67), o que confirma a ocorrência de learning set (Harlow, 1949).

Os dados positivos no teste de discriminação simples $Z 1 / Z 2$, em que todos os participantes escolheram sistematicamente o estímulo Z1, sem treino direto, indicam transferência da função discriminativa para os estímulos do conjunto $\mathrm{Z}$ e formação de classes funcionais entre os estímulos dos conjuntos A e Z (A1 e Z1 na classe dos $\mathrm{S}^{+}$e A2 e Z2 na classe dos $\mathrm{S}^{-}$). Na situação de treino, cada estímulo do conjunto $Z$ foi relacionado condicionalmente com um estímulo do conjunto A. A escolha sistemática do estímulo Z1 sugere que esse estímulo adquiriu a função discriminativa $\left(\mathrm{S}^{\mathrm{D}}\right.$ ou $\left.\mathrm{S}^{+}\right)$do estímulo A1 a que foi correlacionado no treino de discriminações condicionais, ao mesmo tempo em que Z2 adquiriu a função de estímulo delta ou $\mathrm{S}^{-}$do estímulo A2. Esses dados replicam os resultados de Boelens e Smeets (1990) com crianças pré-escolares e do estudo realizado por de Rose et al. (1988) com adultos com retardo, além de contribuírem para a hipótese de que a transferência da função discriminativa é fortemente provável dos estímulos modelo para os estímulos de comparação (Boelens \& Smeets, 1990; de Rose et al., 1988).

Em relação ao desempenho no teste de discriminações condicionais BZ e CZ, os dados sugerem emergência imediata das relações (BZ) para o participante Fábio, e emergência atrasada das relações $\mathrm{CZ}$ para os participantes Bebel, Juca e Fábio. Os participantes Tuco e Nanda apresentaram indícios de emergência das relações BZ e CZ, respectivamente; en- tretanto, a porcentagem de respostas consistentes em reteste não se manteve. De forma geral, os participantes não demonstraram responder emergente na primeira aplicação do teste de discriminações condicionais. Esses resultados sugerem que o ensino de apenas um par de discriminações condicionais (AZ) pode não ter sido suficiente para estabelecer responder condicional generalizado diante de novas tarefas (Smeets \& Barnes, 1997). Os resultados indicativos de emergência atrasada das relações CZ sugerem possíveis efeitos da quantidade de treino (treino de outras relações) sobre a formação de classes funcionais. Resultados de emergência atrasada foram observados, entretanto, apenas em relação ao desempenho de participantes expostos ao ensino de três discriminações simples, e não no caso de participantes expostos ao ensino de duas discriminações simples. Além de terem sido expostos ao ensino de um número menor de discriminações simples, esses participantes não foram expostos ao ensino de um segundo par de discriminações condicionais, o que sugere possíveis efeitos da quantidade de treino sobre a formação de classes. Esses dados replicam resultados da pesquisa realizada por Grisante (2009) com crianças pré-escolares (com cinco anos de idade), que teve como objetivo inicial estabelecer classes de equivalência entre estímulos abstratos. Nesse estudo, em que participaram cinco crianças, era realizado o treino das relações $\mathrm{AB}$ e BC (com três conjuntos de estímulos) e testadas as relações AC e CA. Os resultados indicaram emergência imediata para duas crianças e emergência atrasada para as outras três. O procedimento utilizado com essas três crianças era o retreino das relações $\mathrm{AB}$ e $\mathrm{BC}$ com os mesmos estímulos e reteste; ou o ensino 
de relações com novos estímulos seguidos por novos testes.

Os participantes Juca e Fábio, expostos à segunda etapa do procedimento, aprenderam rapidamente as novas relações condicionais separadas (DZ e EZ), e o número de sessões até atingir o critério passou a ser, em geral, igual ou próximo ao número mínimo previsto. A diminuição do número de sessões até o critério (em comparação à aprendizagem das relações AZ na Etapa 1) evidencia o efeito da exposição ao treino, indicativo de learning set (Harlow, 1949). Além disso, os participantes apresentaram número de erros similar ou menor em comparação aos valores relativos à aprendizagem das relações AZ.

Em relação aos testes de discriminação simples da segunda etapa do procedimento, os resultados de transferência da função discriminativa para os estímulos dos conjuntos $\mathrm{D}$ e E, no caso do participante Fábio, e para o conjunto D, no caso do participante Juca, contradizem dados da literatura que sugerem que a transferência de função discriminativa é mais provável dos estímulos modelo para os estímulos de comparação (de Rose et al., 1988; Boelens \& Smeets, 1990). A partir do treino realizado no presente estudo (DZ e $\mathrm{ZE}$ ), era mais provável que os estímulos do conjunto $E$ adquirissem a função discriminativa dos estímulos do conjunto Z. Os resultados, entretanto, indicaram porcentagens mais altas de respostas consistentes nas tentativas com os estímulos do conjunto D, para os dois participantes. Uma hipótese para explicar esses resultados é a influência da história de reforçamento em que os participantes foram expostos repetidamente à estrutura de treino na qual os estímulos do conjunto $Z$ eram sempre estímulos de comparação (AZ, BZ e CZ), tal como nas relações DZ (estrutura de treino CaN - comparison as node, Saunders, Saunders, Williams, \& Spradlin, 1993) e diferentemente das relações ZE, em que, pela primeira vez, os estímulos do conjunto $\mathrm{Z}$ exerceram função de modelo, o que pode ter favorecido a inclusão dos estímulos D nas classes funcionais.

Os resultados do teste de discriminações condicionais (AD, DA e AE) indicaram desempenho emergente no caso do participante Juca para todas as relações condicionais testadas, e, para o participante Fábio, emergência das relações DA e indícios de emergência das outras relações, AD e AE. Esses resultados sugerem a possibilidade de as classes funcionais previamente estabelecidas funcionarem como classes de equivalência, o que contribui para a hipótese de Sidman (1994), de que o mesmo processo comportamental seria base para os dois tipos de formação de classes.

A oscilação no desempenho do participante Fábio no teste de discriminações condicionais decorreu da ocorrência de erros apresentados especificamente em uma sessão de teste em que a criança emitiu diversos comportamentos concorrentes (falar, cantar, brincar com o mouse), que podem ter sido efeito de variáveis motivacionais, que têm sido apontadas como extremamente relevantes em pesquisas realizadas com crianças pequenas (Gil et al., 2006). Entretanto, as porcentagens de respostas consistentes mais elevadas ocorreram em tentativas em que estímulos do conjunto 1 exerciam função de modelo, e porcentagens mais baixas de respostas consistentes ocorreram em tentativas em que estímulos do conjunto 2 eram modelo. Esse padrão de maior frequência de respostas diante de estímulos de comparação do conjunto 1 
(independente de o modelo ser do conjunto 1 ou do conjunto 2) também ocorreu nos testes de discriminação condicional da Etapa 1 do procedimento (em relação ao desempenho de Fábio, Bebel e Juca). Esses resultados sugerem responder discriminativo simples sob controle da classe de estímulos dos $\mathrm{S}^{+}$.

$\mathrm{O}$ procedimento empregado no presente estudo procurou atender a algumas das exigências propostas em relação ao uso de medidas que atestassem a formação de classes funcionais por meio de testes em condições diferentes das de treino (Saunders, Williams, \& Spradlin, 1996; Sidman, 1994; Wirth \& Chase, 2002) e a possibilidade de essas classes funcionais implicarem classes de equivalência. Em relação a esse aspecto, entretanto, segundo Sidman (1994), a sequência de tentativas de discriminação simples empregada em procedimentos de treino de discriminações simples e reversões repetidas e de discriminações simples misturadas com discriminações condicionais, empregada no procedimento deste estudo, poderia resultar em um treino direto de diversas combinações entre os estímulos ao longo das tentativas, o que implicaria uma forma de ensino direto das relações condicionais que se pretende testar em momentos subsequentes, como no último teste de discriminações condicionais, em que eram testadas as relações AD, DA e AE. Por exemplo, após responder diante de A1 em uma tentativa de discriminação simples em que A1 e A2 eram apresentados, respostas diante de D1 poderiam ser emitidas em uma tentativa de discriminação simples subsequente, em que D1 e D2 eram apresentados. A sequência de responder em A1 e depois em D1, exigida no teste da relação $\mathrm{AD}$, poderia ter sido diretamente treinada a partir da configuração do treino anterior. Por outro lado, a escolha de D2, em tentativas de teste que o estímulo A2 funcionava como modelo, poderia refletir apenas responder por exclusão. Dessa forma, um objetivo futuro deveria ser desenvolver novos procedimentos e testes para verificar se classes funcionais podem resultar em classes de equivalência.

Considera-se, ainda, que investigações subsequentes deveriam investigar a viabilidade de procedimentos mais econômicos para promover a formação de classes funcionais, considerando a longa exposição a condições de treino dos participantes que realizaram todo o procedimento previsto, apesar de o número de blocos de treino realizados até o critério ter sido em geral próximo da quantidade mínima programada. Isso sugere que o número mínimo de blocos programados pode ter sido maior do que o mínimo necessário para estabelecer linhas de base consistentes, por exemplo, nas etapas de ensino gradual (treino blocado de tentativas consecutivas com o mesmo modelo e diminuição gradual até apresentação randômica).

De forma geral, portanto, os dados obtidos neste estudo demonstraram a viabilidade do emprego do procedimento de ensino de discriminações simples e condicionais e testes de transferência de função para o estabelecimento de classes funcionais. $\mathrm{O}$ emprego desse procedimento como uma alternativa ao emprego de reversões de discriminações simples parece ter minimizado a ocorrência de erros durante as fases de ensino, permitindo a formação de classes funcionais para parte dos participantes. Esses resultados replicam aqueles encontrados em estudo prévio, em que foi empregado o procedimento de 
treino de discriminações simples e reversões (Lionello-DeNolf et al., 2008). Os resultados do presente estudo, em que alguns dos participantes demonstraram formação de classes, sugerem, portanto, o papel de outras variáveis, não identificadas ou não descritas, no processo de formação de classes e na explicação da variabilidade entre participantes, além da influência de padrões de erros.

\section{REFERÊNCIAS}

Boelens H., \& Smeets, P. (1990). An analysis of emergent simple discrimination in children. The Quarterly Journal of Experimental Psychology, 42B, 135-152.

Canovas, D. S. (2010). Discriminações simples - simultâneas e sucessivas - na formação de classes funcionais (Dissertação de mestrado). Universidade Federal de São Carlos, São Carlos, SP, Brasil.

de Rose, J. C. C. (1993). Classes de estímulos: implicações para uma análise comportamental da cognição. Psicologia: Teoria e Pesquisa, 9, 283-303. de Rose, J. C., McIlvane, W. J., Dube, W.V., \& Stoddard, L. T. (1988). Stimulus class formation and functional equivalence in moderately retarded individuals' conditional discrimination. Behavioral Processes, 17, 167-175.

Devany, J. N., Hayes, S. C., \& Nelson, R. O. (1986). Equivalence class formation in language-able and language-disabled children. Journal of the Experimental Analysis of Behavior, 46, 243-457.

Dube, W.V. (1991). Computer software for stimulus control research with Macintosh computers. Experimental Analysis of Human Behavior Bulletin, 9, 28-39.

Dube, W. V., Callahan, T. D., \& McIlvane, W. J. (1993). Serial reversals of concurrent auditory discrimination in rats. The Psychological Record, 43, 429-440.
Dube, W.V., \& Hiris, E. J. (1996). MTS v 11.6. E. K. Shriver Center for Mental Retardation, Inc. (Software desenvolvido somente para Pesquisa e Educação).

Dunn, L. M., \& Dunn, L. M. (1981). Peabody vocabulary test - revised. Minnesota: American Guidance Service.

Gil, M. S. C. A., Oliveira, T. P., de Sousa, N. M., \& Faleiros, D. A. M. (2006).Variáveis no ensino de discriminação para bebês. Psicologia Teoria e Pesquisa, 22, 143-152.

Goldiamond, I. (1962). Perception. In A. J. Bachrach (Org.). Experimental foundations of clinical psychology (pp. 280-340). New York: Basic Books.

Goldiamond, I. (1966). Perception, language and conceptualization rules. In B. Leinmuntz (Org.). Problem solving (pp. 183-214). New York: Wiley.

Grisante, P. C. (2009). Controle de estímulos e formação de relações simbólicas em pré-escolares e indivíduos com síndrome de Down (Texto de qualificação). Programa de Pós-Graduação em Educação Especial, Universidade Federal de São Carlos, São Carlos, SP, Brasil.

Harlow, H. F. (1949). The formation of learning sets. Psychological Review, 56, 51-65.

Harzem, P., \& Miles, T. R. (1978). Conceptual issues in operant psychology. Chicheste: Wiley.

Jordan, C. R., Pilgrim, C., \& Galizio, M. (2001). Conditional discrimination and stimulus equivalence in young children following three different baseline training procedures. Experimental Analysis of Human Behavior Bulletin, 19, 3-7.

Keller, F. S., \& Schoenfeld, W. N. (2004). Princípios de psicologia (C. M. Bori \& R. Azzi, Trad.). São Paulo: EPU. (Obra original publicada em 1950). Lionello-DeNolf, K., McIlvane, W. J., Canovas, D. S., de Souza, D. G., \& Barros, R. S. (2008). Reversal learning set and functional equivalence in children with and without autism. The Psychological Record, 58, 15-36. 
Lipkens, R., Hayes S. C., \& Hayes L. J. (1993). Longitudinal study of the development of derived relations in an infant. Journal of Experimental Child Psychology, 56, 201-239.

McIlvane, W. J., \& Dube, W.V. (2003). Stimulus control topography coherence theory: Foundations and extensions. The Behavior Analyst, 26, 195-213.

Oliveira, T. P., \& Gil, M. S. C. A. (2008). Condições experimentais facilitadoras para a aprendizagem de discriminação por bebês. Psicologia: Teoria $e$ Pesquisa, 24, 5-18.

Pedromônico, M. R. M., Bargatto, E. L., \& Strobilus, R. (1999). Teste de triagem Denver II. São Paulo: Unifesp.

Pilgrim, C., Jackson, J., \& Galizio, M. (2000). Acquisition of arbitrary conditional discriminations by young normally developing children. Journal of the Experimental Analysis of Behavior, 73, 177-193.

Saunders, K. J., Saunders, R. R., Williams, D. C., \& Spradlin, J. E. (1993). An interaction of instructions and training design on stimulus class formation: Extending the analysis of equivalence. The Psychological Record, 43, 725-744.

Saunders, K. J., \& Spradlin, J. E. (1989). Conditional discrimination in mentally retarded adults: The effect of training the component simple discriminations. Journal of the Experimental Analysis of Behavior, 52, 1-12.

Saunders, K. J., \& Spradlin, J. E. (1990). Conditional discrimination in mentally retarded adults: The development of generalized skills. Journal of the Experimental Analysis of Behavior, 54, 239-250.

Saunders, K. J., \& Spradlin, J. E. (1993). Conditional discrimination in mentally retarded subjects: Programming acquisition and learning set. Journal of the Experimental Analysis of Behavior, 60, 571-585.

Saunders, K. J., Williams, D. C., \& Spradlin, J. E. (1996). Derived stimulus control: Are there dif- ferences among procedures and processes? In $\mathrm{T}$. R. Zental \& P. M. Smeets (Eds.). Stimulus class formation in humans and animals (pp. 93-109). Amsterdam: Elsevier.

Sidman, M. (1960). Tactics of scientific research: Evaluating experimental data in Psychology. New York, NY: Basic Books / Boston, MA: Authors Cooperative.

Sidman, M. (1994). Equivalence relations and behavior: A research history. Boston, MA:Authors Cooperative. Sidman, M. (2000). Equivalence relations and the reinforcement contingency. Journal of the Experimental Analysis of Behavior, 74, 127-146.

Smeets, P. M., \& Barnes, D. (1997). Emergent conditional discriminations in children and adults: Stimulus equivalence derived from simple discrimination. Journal of Experimental Child Psychology, 66, 64-84.

Smeets, P. M., Barnes, D., \& Roche, B. (1997). Functional equivalence in children: Derived stimulusresponse and stimulus-stimulus relations. Journal of Experimental Child Psychology, 66, 1-17.

Stoddard, L. T., de Rose, J. C., \& McIlvane, W. J. (1986). Observações curiosas acerca do desempenho deficiente após a ocorrência de erros. Psicologia, 12, 1-18.

Vaughan, W. (1988). Formation of equivalence sets in pigeons. Journal of Experimental Psychology: Animal Behavior Processes, 14, 36-42.

Wirth, O., \& Chase, P. N. (2002). Stability of functional equivalence and stimulus equivalence: Effects of baseline reversals. Journal of the Experimental Analysis of Behavior, 77, 29-47.

Nota das autoras: O artigo é baseado em dissertação submetida pela primeira autora ao Programa de Pós-Graduação em Psicologia da Universidade Federal de São Carlos, como parte dos requisitos para obtenção do título de Mestre em Psicologia. A primeira 
autora teve bolsa de Mestrado da Fapesp. A segunda autora é bolsista de doutorado da Fapesp. A terceira autora é bolsista de produtividade em pesquisa do CNPq. A pesquisa foi apoiada pela Fundação de Amparo à Pesquisa do Estado de São Paulo (Fapesp, Processo $\mathrm{n}^{\mathrm{o}}$ 03/09928-4). Todas as autoras são afiliadas ao Instituto Nacional de Ciência e Tecnologia sobre Comportamento, Cognição e Ensino, financiado pelo Conselho Nacional de Ciência de Tecnologia (CNPq
- Processo no 573972/2008-7) e pela Fapesp (Processo $n^{\circ}$ 08/57705-8), que apoiou a preparação do artigo.

As autoras agradecem a Maria Stella Gil os comentários construtivos sobre a pesquisa e a redação do artigo, e a William Dube a autorização para uso do software MTS.

Correspondência para Daniela S. Canovas: Avenida Itaboraí, 321, apto. 44B, Bosque da Saúde; São Paulo/SP - CEP 04135-000. E-mail:danielacanovas@gmail.com. 